\title{
Synthesis of poly[oligo(hexafluoropropylene oxide) perfluoroisopropenylether (PIPE)] graft copolymers with vinylidene fluoride (VDF) using $\mathrm{CF}_{3}$ radicals
}

Trevor J. Burgess ${ }^{1}$, Alessandra Vitale ${ }^{2}$,Christine Joly-Duhamel ${ }^{3}$, Roberta Bongiovanni ${ }^{2}$, Abdelatif Manseri ${ }^{3}$, Taizo Ono ${ }^{4}$, Bruno Améduri ${ }^{3 *}$ and Chadron M. Friesen ${ }^{1^{*}}$

${ }^{1}$ Department of Chemistry, Trinity Western University, Langley, British Columbia, V2Y 1Y1, Canada.

Email: chad.friesen@twu.ca

${ }^{2}$ Department of Applied Science and Technology, Politecnico di Torino, 10129 Torino, Italy

${ }^{3}$ Institut Charles Gerhardt, ICGM, UMR 5253 CNRS Université de Montpellier, CNRS, ENSCM, Team IAM Place Eugène Bataillon, 34095 Montpellier Cedex 5, France

${ }^{4}$ Fluorine Division, Research \& Development Center, Mitsubishi Materials Electronic Chemicals Co., Ltd. 31-6 Barajima, Akita city, Akita 010-8585, Japan

KEYWORDS : fluoropolymer; perfluoroisopropenyl ethers; graft copolymers; hexafluoropropylene oxide; ${ }^{19}$ F-NMR spectroscopy; radical copolymerization; thermal properties; vinylidene fluoride.

Abstract. The synthesis of poly(vinylidene fluoride)-graft-oligomeric hexafluoropropylene oxide graft copolymers [poly[VDF-g-oligo(HFPO)-PIPE] is presented, where VDF, HFPO, and PIPE stand for vinylidene fluoride $\left(\mathrm{CH}_{2}=\mathrm{CF}_{2}\right)$, hexafluoropropylene oxide $\left(\mathrm{CF}_{3} \mathrm{CFCF}_{2} \mathrm{O}\right)$ and, perfluoroisopropenylether ($\left.\mathrm{OC}\left(\mathrm{CF}_{3}\right)=\mathrm{CF}_{2}\right)$, respectively. First, an $82 \%$ isolated yield of oligo(HFPO)-PIPE macromonomer was achieved by using oligo(HFPO) primary iodide as the starting reagent. Then, the radical copolymerization of VDF with the PIPE comonomer, initiated by perfluoro-3-ethyl-2,4-dimethyl-3-pentyl persistent radical (PPFR), was studied under various conditions. The PPFR initiator, stable at room temperature, was able to release a ${ }^{\circ} \mathrm{CF}_{3}$ radical starting from $80{ }^{\circ} \mathrm{C}$. The resulting poly[VDF-g-oligo(HFPO)-PIPE] graft copolymers were produced in good isolated yields (76 to 97\%). The molar percentages and molar masses of such graft copolymers were assessed by ${ }^{19}$ F-NMR spectroscopy using the $\mathrm{CF}_{3^{-}}$end-group label. The molar percentages of VDF and oligo(HFPO)-PIPE comonomers reached up to $99 \%$ and $20 \%$, respectively, while the molar masses ranged between 7,500 and 42,600 g.mol ${ }^{-1}$. Their thermal properties showed: i) fair to satisfactory thermostability $\left(\mathrm{T}_{\mathrm{d}}{ }^{5 \%}\right)$ showing up to $271^{\circ} \mathrm{C}$ under nitrogen, ii) glass transition $\left(\mathrm{T}_{\mathrm{g}}\right)$ ranged from -81 to $-82{ }^{\circ} \mathrm{C}$ while iii) their melting temperature $\left(\mathrm{T}_{\mathrm{m}}\right)$ ranged between 150 and $163{ }^{\circ} \mathrm{C}$. Moreover the synthesized copolymers were demonstrated to be highly omniphobic (i.e., simultaneously hydrophobic and 
oleophobic), showing a water contact angle of ca. $133^{\circ}$, a hexadecane contact angle ca. $70^{\circ}$, and a surface energy as low as $12 \mathrm{mN} / \mathrm{m}$.

\section{Introduction}

Fluorinated elastomers are specialty polymers with outstanding properties for many applications. ${ }^{1,2}$ They can be either poly(phosphazenes), ${ }^{3}$ fluorosilicones or thermoplastic elastomers. ${ }^{1}$ Certainly perfluoroalkylvinyl ether monomers (PAVE), such as $\mathrm{C}_{n} \mathrm{~F}_{2 n+1} \mathrm{OCF}=\mathrm{CF}_{2}$, where $\mathrm{n}=1$ to 3 , are widely used in commercial products utilizing radical polymerization with tetrafluoroethylene (TFE) to form fluoroelastomers known as perfluoroalkoxyl polymer (PFA). The co-monomer, perfluorovinyl ether, interferes with the crystallizability of PTFE and allows for better melt processing ability while maintaining good mechanical properties. This all done without sacrificing chemical resistance and thermal performance, having a continuous service temperature of $260{ }^{\circ} \mathrm{C} .{ }^{4}$ These PFA polymers are resistant to aggressive chemicals, allowing for their use in corrosion-resistant lining of vessels, encapsulated o-rings, medical tubing, heat exchangers, semi-conductor baskets, valve liners, pumps and fittings, electrical insulation, insulator bushes, nozzles applications and many more. ${ }^{5}$

Other researchers discovered further utility of the perfluoroalkenyloxy moiety by changing the mode of radical polymerization to cycloaddition. For example, Smith and Wu's research groups explored perfluorovinyl ether linked to aromatics to eventually create perfluorocyclobutyl-bridged polymers through a $[2+2]$ cycloaddition reaction. ${ }^{6}$ These materials are found to be useful in electro-optic applications. More recently, oligo(HFPO)-PVE based macromonomers (where PVE is $-\mathrm{OCF}=\mathrm{CF}_{2}$ ) were demonstrated to copolymerize with VDF to create novel graft copolymer, [poly(VDF-g-oligo(HFPO)-PVE)], with low glass transition temperatures $\left(-79\right.$ to $\left.-54{ }^{\circ} \mathrm{C}\right)$, good thermal stability $\left(410\right.$ to $494{ }^{\circ} \mathrm{C}$ range under air), and melting temperatures $\left(138\right.$ to $\left.159{ }^{\circ} \mathrm{C}\right) .^{7}$ In addition, Lopez et al., demonstrated that click chemistry can be utilized with telechelic perfluoropolyalkylethers (PFPAE) to form a new library of elastomers with the lowest glass transition temperatures evidenced at $-105{ }^{\circ} \mathrm{C}$ and thermal stability averaging around $200{ }^{\circ} \mathrm{C}$ under air. ${ }^{8}$

An expansion of this work beyond perfluorovinylethers with PFPAE was considered since pentafluoro1-methylvinyl $t$-butyl carbonate monomer $\left[\mathrm{CF}_{2}=\mathrm{C}\left(\mathrm{CF}_{3}\right) \mathrm{OC}(\mathrm{O}) \mathrm{C}\left(\mathrm{CH}_{3}\right)_{3}\right]$ was demonstrated to be useful in 
the formation of terpolymer of molar masses of $4.5 \times 10^{4} \mathrm{M}_{\mathrm{n}}$ for use as $157 \mathrm{~nm}$ photoresists. ${ }^{9}$ Other works used perfluoroisopropenyl esters. Specifically, Narita demonstrated that bis( $\alpha$-trifluoromethyl- $\beta$ difluorovinyl) terephthalate $\left[\mathrm{CF}_{2}=\mathrm{C}\left(\mathrm{CF}_{3}\right) \mathrm{OCOC}_{6} \mathrm{H}_{4} \mathrm{COOC}\left(\mathrm{CF}_{3}\right)=\mathrm{CF}_{2}\right]$ could radically polymerize with 1,4dioxane through a radical polyaddition mechanism with cyclic ethers, using benzoyl peroxide (BPO) or with $\gamma$-rays to generate polymers up to $1.5 \times 10^{4} \mathrm{M}_{\mathrm{n}} \cdot{ }^{10,11}$ When gamma rays were used then higher molecularweight polymers were possible compared with those initiated with BPO. The Hitachi Company, utilizing this same chemistry, accomplished radical polyaddition with crown ethers for application in lithium ion secondary batteries. ${ }^{12}$ Their new materials exhibited high ionic conductivity and the electrolyte exhibited superior charge and discharge characteristics. Water repellant material can also be made if radical polyaddition of perfluoroisopropenyl ester is polymerized with silsequioxane, resulting in polymer molar masses of $2.5 \times 10^{5} \mathrm{M}_{\mathrm{n}}{ }^{13}$ Lastly, it was found that this ester was useful in polymerizing vinyl compounds such as $\mathrm{N}$-vinylcarbazole $\left(5.16 \times 10^{4} \mathrm{M}_{\mathrm{n}}\right)$ and butylvinylether $\left(1.57 \times 10^{5} \mathrm{M}_{\mathrm{n}}\right)$ catalytically at $-78{ }^{\circ} \mathrm{C}$ in toluene. $^{14}$

Beyond these applications, synthetic strategies were also reviewed to construct a perfluoroisopropenyl group. For example, Storey and co-workers reported a 79\% yield of ethyl pentafluoroisopropenyl ether $\left(\mathrm{EtOC}\left(\mathrm{CF}_{3}\right)=\mathrm{CF}_{2}\right)$ by adding triethylphosphite $\left[\mathrm{P}(\mathrm{OEt})_{3}\right]$ to hexafluoroacetone at $-60{ }^{\circ} \mathrm{C} .{ }^{15}$ Huang and Kudzma reported a very low yielding pentafluoroisopropenyl ether (6\%) which was accessed by a sevoflurane derivative $\left(\mathrm{CH}_{2} \mathrm{FOC}\left(\mathrm{CF}_{3}\right)=\mathrm{CF}_{2}\right)$ using lithium bis(trimethylsilyl)amide (LiHMDS) to dehydrofluorinate sevoflurane $\left(\mathrm{CH}_{2} \mathrm{FOCH}\left(\mathrm{CF}_{3}\right)_{2}\right) .{ }^{16}$ Nakai described a perfluoroisopropenyl ester rather than an ether via the lithium enolate prepared from hexafluoroisopropanol (HFIP) and benzoyl chloride yielding an $82 \%$ isolated product. ${ }^{17}$ While this final route is facile and accessible from acid fluorides of oligo(HFPO), we primarily sought to find a synthesis for the PIPE over the ester, since ether linkages tend to withstand harsher environments. In 2018, we communicated the formation of oligo(HFPO)-PIPE. ${ }^{18}$ The best route to PIPE was using oligo(HFPO) primary iodide and treating the iodide with one equivalent of phenyl lithium at $-78{ }^{\circ} \mathrm{C}$ in perfluorohexane/hexane mixture and then proceeding to slowly warm up the mixture to room temperature over 4 hours. 
Since our experimental work quickly showed that [2+2] cycloaddtions would not be likely, this work aims at demonstrating whether oligo(HFPO)-PIPE could copolymerize with VDF under radical conditions. We also wanted to explore whether an increase in branching on the olefinic macromonomer would lead to lower glass transition temperatures for polymers with VDF, as compared to oligo(HFPO)-PVE. We have chosen $\cdot \mathrm{CF}_{3}$ radical generated by a persistant perfluororadical initiator (PPFR) for its efficiency with fluoromonomers. The thermal and wettability properties of the resulting copolymers have been studied and discussed.

\section{Experimental section}

\subsection{Materials.}

All reagents were used as received unless it is stated. 1,1-Difluoroethylene (vinylidene fluoride, VDF) was kindly supplied by Arkema (Pierre-Benite, France). The persistent radical (PPFR) was synthesized as reported as before. oligo(hexafluoropropylene oxide) primary iodide and 1,1,2-trichloro-1,2,2trifluoroethane (Freon ${ }^{\circledR}$ 113) were kindly offered by DuPont (Wilmington, USA). Deuterated dimethylformamide (DMF- $\mathrm{d}_{7}$ ) used for the NMR spectroscopy was purchased from Euroiso-top (Grenoble, France) (purity>99.8\%). Perfluoro-buthyl/isobutyl methyl ether, HFE-7100, was purchased from 3M (USA). Pentafluorocinnamic acid, methanol, dibutyl ether, phenyl lithium, acetone, hexanes, perfluorohexane, lithium chloride, dimethylformamide (DMF), tetrahydrofuran (THF), trifluorotoluene, N-benzylbenzamide where purchased from Sigma Aldrich (Canada). The $3 \mathrm{~mm}$ magnetic stir-bar for the Carius tube was purchased from Carl Roth Gmbh Co. D 76185 Karlsruhe, Germany.

\subsection{Analysis}

Nuclear Magnetic Resonance (NMR) spectroscopy: The structure of the products was determined by NMR spectroscopy at room temperature $\left(25^{\circ} \mathrm{C}\right)$. NMR spectra were recorded on Bruker AC-400 instruments using a deuterated benzene capillary as an internal reference. The experimental conditions were accomplished using TopSpin 2.1 operating at $400.13\left({ }^{1} \mathrm{H}\right), 376.46\left({ }^{19} \mathrm{~F}\right), 100.62\left({ }^{13} \mathrm{C}\right) \mathrm{MHz}$. Flip angle $90^{\circ}$ for ${ }^{1} \mathrm{H}$ and ${ }^{13} \mathrm{C}$ and $30^{\circ}$ for ${ }^{19} \mathrm{~F}-\mathrm{NMR}$; acquisition time $3.96 \mathrm{~s}\left({ }^{1} \mathrm{H}\right), 0.87 \mathrm{~s}\left({ }^{19} \mathrm{~F}\right), 1.36 \mathrm{~s}\left({ }^{13} \mathrm{C}\right)$; pulse delay $2 \mathrm{~s}$ $\left({ }^{1} \mathrm{H}\right), 4 \mathrm{~s}\left({ }^{19} \mathrm{~F}\right.$ and $\left.{ }^{13} \mathrm{C}\right)$; scans $128\left({ }^{1} \mathrm{H}\right), 16\left({ }^{19} \mathrm{~F}\right), 6144\left({ }^{13} \mathrm{C}\right)$; and pulse width of $12.5\left({ }^{1} \mathrm{H}\right), 13.0\left({ }^{19} \mathrm{~F}\right)$, and 9.0 
$\left({ }^{13} \mathrm{C}\right) \mu \mathrm{s}$. The letters $\mathrm{b}, \mathrm{s}, \mathrm{d}, \mathrm{t}, \mathrm{q}$, and sext stand for broad, singlet, doublet, triplet, quartet, and sextet, respectively.

Using ${ }^{19}$ F-NMR spectroscopy, it is possible to calculate :

The molar percentages of VDF (Equation 1) or oligo(HFPO)-PIPE (Equation 2) in the copolymer:

Mole \% of VDF =

$$
\frac{\left(\int_{-90}^{-96} \mathrm{CF}_{2(V D F)}+\int_{-109}^{-111} \mathrm{CF}_{2(V D F)}+\int_{-113}^{-117} \mathrm{CF}_{2(V D F)}\right)}{\left(\int_{-90}^{-96} \mathrm{CF}_{2(V D F)}+\int_{-109}^{-111} \mathrm{CF}_{2(V D F)}+\int_{-113}^{-117} \mathrm{CF}_{2(V D F)}+\int_{-111}^{-113} \mathrm{CF}_{2(\text { oligo }[H F P O]-P I P E)}\right)} \times 100 \%
$$

where $\int_{-b}^{-j} C F_{2}$ stands for the integral of the difluoromethylene signals centered from $-\mathrm{b}$ to $-\mathrm{j}$

Mole \% of oligo(HFPO)-PIPE $=100-$ mole $\%$ VDF

\section{Average $M_{n}$ copolymer initiated by $P P F R=$}

$$
\frac{64 \frac{g}{m o l} \times\left[\frac{\left(\int_{-90}^{-96} \mathrm{CF}_{2(V D F)}+\int_{-109}^{-111} \mathrm{CF}_{2(V D F)}+\int_{-113}^{-117} \mathrm{CF}_{2(V D F)}\right)}{2}\right]+1478 \frac{g}{\mathrm{~mol}} \times\left[\frac{\left(\int_{-111}^{-113} \mathrm{CF}_{2(\text { oligo }(H F P O-P I P E)}\right)}{2}\right]}{\frac{\left(\int_{-60}^{-62} \mathrm{CF}_{3(P P F R)}\right)}{6}}+\left(2 \times 69 \frac{\mathrm{g}}{\mathrm{mol}}\right)
$$

With the molecular weight of VDF (64 g.mol ${ }^{-1}$ ), oligo(HFPO)-PIPE (1478 g.mol ${ }^{-1}$ ), the $\mathrm{CF}_{3^{-}}$ terminus-groups $\left(69\right.$ g.mol $\left.{ }^{-1}\right)$, and the area amounts of the difluoromethylene signals in ${ }^{19} \mathrm{~F}-\mathrm{NMR}$ for VDF and PIPE,

The normal and the reverse portions of the polymer (rates of inversion to VDF (Tail to Tail and Head to))

$$
\begin{gathered}
{ }^{1} H \% \text { inversion }=\left[\left(\frac{\int_{2.0}^{2.4} I}{\int_{2.0}^{2.4} I+\int_{2.7}^{3.3} I}\right) / 2\right] \times 100 \\
{ }^{19} \mathrm{~F} \% \text { inversion }=\left[\frac{\int_{-116}^{-116.5} I}{\int_{-90}^{-95} I+\int_{-113.5}^{-114} I+\int_{-116}^{-116.5} I}\right] \times 100
\end{gathered}
$$

With the $\int_{-90}^{-96} C F_{2}$ integral which is the normal head-to-tail portion (normal addition in the VDF-VDF dyad) of the VDF and the $\int_{-109}^{-111} C F_{2}$ integral which corresponds to the VDF units next to the $-\mathrm{CF}_{2}-$ backbone of the $-\mathrm{CF}_{2} \mathrm{C}\left(\mathrm{CF}_{3}\right)\left(\right.$ oligo(HFPO))- macromonomer unit, with the $\int_{-113}^{-117} C F_{2}$ integral which is the head-to-head additon (or reversed VDF-VDF dyad) of the VDF in the graft copolymer. 
Matrix Assisted Laser Desorption Ionization-Time-Of-Flight mass spectrometry (MALDI-TOF-MS):

Experiments were determined with a Bruker Ultraflex III with a positive ionization method for compounds containing a higher content of hydrocarbons and a negative ionization method for compounds higher in fluorocarbon content. For sample preparation, the first solution is made by adding $0.5 \mathrm{~g}$ of $2,3,4,5,6$ pentafluorocinnamic acid to a $50 \mathrm{~mL}$ flask followed by the addition of $12.5 \mathrm{~mL}$ of the solvents HFE-7100 and methanol. To prepare the macromonomer for analysis, 2 to 3 drops of it is added to a $1.5 \mathrm{~mL}$ vial followed by an addition of $1 \mathrm{~mL}$ of the previously prepared $20 \mathrm{~g} / \mathrm{L}$ perfluorocinnamic acid in HFE$7100 /$ methanol solution and vortexed. $1 \mu \mathrm{l}$ of the prepared sample containing and matrix solution is then withdrawn and added to the stainless steel MALDI plate followed by $1 \mu \mathrm{L}$ of cationization agent $(10 \mathrm{mg} / \mathrm{mL}$ solution of lithium chloride in methanol).

Thermogravimetric analyses (TGA): Thermogravimetric analyses were performed with a Mettler Toledo TGA/SDTA $851^{\mathrm{e}}$ apparatus under nitrogen $(60 \mathrm{~mL} / \mathrm{min})$ at a heating rate of $10{ }^{\circ} \mathrm{C} \cdot \mathrm{min}^{-1}$ from $25{ }^{\circ} \mathrm{C}$ up to a maximum of $800{ }^{\circ} \mathrm{C}$, using an alumina pan. The sample size varied between 10 and $15 \mathrm{mg}$. The first derivative of the weight loss profile was calculated in order to identify the main degradation peaks of the systems.

Differential Scanning Calorimetry (DSC): Differential Scanning Calorimetry measurements were conducted using a Netzsch DSC 200F3 Maia ${ }^{\circledR}$ instrument connected to a micro-computer. The apparatus was calibrated with indium and $n$-decane. After its insertion into the DSC apparatus, the sample at $20{ }^{\circ} \mathrm{C}$ was initially cooled $10{ }^{\circ} \mathrm{C} \cdot \mathrm{min}^{-1}$ until it reached $-150{ }^{\circ} \mathrm{C}$ for $2 \mathrm{~min}$. Then, the first scan was operated at a heating rate of $10{ }^{\circ} \mathrm{C} \cdot \mathrm{min}^{-1}$ up to $250{ }^{\circ} \mathrm{C}$. A second scan was required for the assessment of the $\mathrm{T}_{\mathrm{g}}$, defined as the inflection point in the heat capacity jump, and $\mathrm{T}_{\mathrm{m}}$, defined as the maximum of the endothermic peak. The sample size was about $10-15 \mathrm{mg}$.

Crystallinity: The degrees of crystallinity of the copolymers were determined using (Equation 6):

Degree of crystallinity $(\chi)=\frac{\Delta H_{m}}{\Delta H_{c}} \times 100$ 
where $\Delta H_{c}\left(104.5 \mathrm{~J} \mathrm{~g}^{-1}\right)$ corresponds to the enthalpy of melting of a $100 \%$ crystalline $\mathrm{PVDF}^{19,20}$ and $\Delta H_{m}$ is the heat of fusion of the copolymer (determined by DSC in $\mathrm{J} \mathrm{g}^{-1}$ ).

Wettability: Wettability of thin films was assessed by static contact angle $(\theta)$ measurements with water $(\gamma=$ $\left.72.1 \mathrm{mN} \mathrm{m}^{-1}\right)$ and hexadecane $\left(\gamma=28.1 \mathrm{mN} \mathrm{m}^{-1}\right)$ by means of a FTA 1000C instrument (First Ten Ångstroms), equipped with a video camera and image analyzer, at room temperature with the sessile drop technique. On each surface at least five angles were measured immediately after the droplet deposition: the mean value and the standard deviation were determined.

The surface energy $\gamma$ was calculated by the Owens-Wendt geometric mean method (Equation 7):

$\gamma_{l}(1+\cos \theta)=2 \sqrt{\gamma^{d} \gamma_{l}^{d}}+2 \sqrt{\gamma^{p} \gamma_{l}^{p}}$

where $\gamma^{d}$ and $\gamma^{p}$ are the dispersive and the polar components of the surface energy $\gamma$ of the polymer, respectively, $\theta$ is the contact angle between the polymer and the test liquid, and $\gamma_{l}$ is the surface tension of the test liquid, formed by a dispersive $\left(\gamma_{l}^{d}\right)$ and a polar $\left(\gamma_{l}^{p}\right)$ part.

\subsection{Characterization of the PPFR, Synthesis of Monomer, and Radical Polymerization}

\subsubsection{PPFR Initiator}

PPFR was synthesized by known procedures. ${ }^{21,22}$ The fraction collected at $31-33{ }^{\circ} \mathrm{C} / 25 \mathrm{mmHg}$ was used for this investigation.

Characterization: The ${ }^{19}$ F-NMR data on the products (E- and Z- forms of perfluoro-3-ethyl-4-methyl-2pentene) obtained by the thermal decomposition of the persistent perfluoroalkyl radical are as follows ${ }^{21,22}$ :

1. E-form: $-62.9(\mathrm{~m}, 3 \mathrm{~F}),-79.4\left(\mathrm{~d},{ }^{3} \mathrm{~J}_{\mathrm{FF}}=29.3 \mathrm{~Hz}, 6 \mathrm{~F}\right),-80.5\left(\mathrm{~d},{ }^{3} \mathrm{~J}_{\mathrm{FF}}=20.3 \mathrm{~Hz}, 3 \mathrm{~F}\right),-81.3$ (overlapped, 1F), $-103.3(\mathrm{~m}, 2 \mathrm{~F}),-175.9(\mathrm{~m}, 1 \mathrm{~F})$

2. Z-form: $-62.7\left(\mathrm{~d},{ }^{3} \mathrm{~J}_{\mathrm{FF}}=48.5 \mathrm{~Hz}, 3 \mathrm{~F}\right),-72.1(\mathrm{~s}, 6 \mathrm{~F}),-79.1$ (overlapped, 4F), -103.5 (m, 2F), -170.1 (quartet, ${ }^{3} \mathrm{~J}_{\mathrm{FF}}=48.5 \mathrm{~Hz}, 1 \mathrm{~F}$ ).

Thermal decomposition ${ }^{21}$ : Decomposition is a first order reaction $(\ln ([\mathrm{PPFR}] /[\mathrm{PTFA}])=-0.718 \mathrm{t}+1.479, \mathrm{r}$ $=0.999)$. The half-life at $90{ }^{\circ} \mathrm{C}$ was assessed as $0.97 \mathrm{~h}$. 


\subsubsection{Synthesis of oligo(hexafluoropropylene oxide)-PIPE}

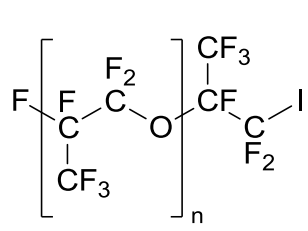

1) 1.0 eq. PhLi

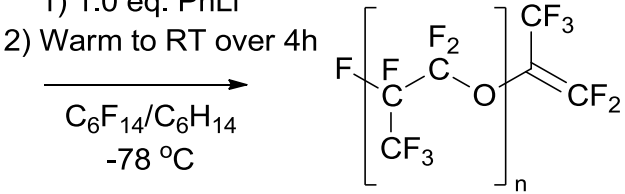

oligo(HFPO)

Perfluorisopropenyl ether

(PIPE)

Scheme 1: The formation of PIPE using oligo(hexafluoropropylene oxide) primary iodide and phenyl lithium in a 50/50 mole ratio of hexane and perfluorohexane.

PIPE monomer was synthesized following the reaction reported in Scheme $1 .{ }^{18}$ A $50 \mathrm{~mL}$ three-necked round-bottomed flask with a magnetic stir bar was removed from the drying oven and quickly fitted with an elbow stopcock gas inlet adaptor, glass stopper, and rubber septum. All glass-glass joints were sealed with Dow Corning® high-vacuum grease. The system was immediately connected to nitrogen gas via a Schlenk line and allowed to purge while cooling for 15 minutes. The flask was then charged with fresh phenyl lithium solution of recently determined titre in dibutyl ether $(3.41 \mathrm{~mL}, 6.16 \mathrm{mmol}, 1.80 \mathrm{M})$ by syringe. The phenyl lithium was then dried in vacuo (2 Torr) to give a tan powder after 1 hour. The flask was slowly back-filled with nitrogen, and the contents were diluted and agitated in $3 \mathrm{~mL}$ of scrupulously anhydrous hexanes to a cloudy white solution. The solution was then cooled to $-78{ }^{\circ} \mathrm{C}$ with stirring in an insulated bath of dry ice/acetone.

A second $50 \mathrm{~mL}$ three-necked round-bottomed flask with a magnetic stir bar was fitted as above, and then purged with nitrogen while cooling to room temperature. 1.00 molar equivalents of previously degassed oligo(hexafluoropropylene oxide) primary iodide $(10.0 \mathrm{~g}, 6.16 \mathrm{mmol})$ was added by weighed syringe. This oil was diluted in $5 \mathrm{~mL}$ of anhydrous perfluorohexane while stirring, and then cooled to $-78{ }^{\circ} \mathrm{C}$ in an insulated dry ice/acetone bath. After cooling for $45 \mathrm{~min}$, the fluorous solution was transferred by syringe to the flask containing phenyl lithium in hexanes, using an additional $2 \mathrm{~mL}$ perfluorohexane rinse to facilitate quantitative transfer.

The reaction mixture in the insulated dry ice/acetone bath was allowed to slowly warm to room temperature with continuous stirring over 3-4 hours, followed by quenching with $0.5 \mathrm{~mL}$ of deionized water. The solvent 
was removed in vacuo at room temperature in an oil bath. The remaining oligo(HFPO) product was washed 3 times with glacial acetic acid, 3 times with ice cold diethyl ether and then isolated under vacuum to afford clear, light yellow oil containing $27 \%$ unreactive hydrogen end-capped material $(7.5 \mathrm{~g}, 82 \%$ isolated yield with $63 \%$ purity).

Characterization: ); $\delta{ }^{19} \mathrm{~F}$ NMR (376 MHz, $\mathrm{C}_{6} \mathrm{D}_{6}, 25{ }^{\circ} \mathrm{C}$, see Figure $\left.\mathrm{S} 1\right)$ : $-66.50\left(\mathrm{~m},-\mathrm{C}\left(\mathrm{CF}_{\mathbf{3}}\right)=\mathrm{CF}_{\mathrm{a}} \mathrm{F}_{\mathrm{b}}, 3 F\right),-80$ $\left(\mathrm{m},-\mathrm{CF}\left(\mathrm{CF}_{3}\right) \mathrm{CF}_{2} \mathrm{O}-\right),-82.41\left(\mathrm{~s}, \mathrm{C}_{\mathbf{F}} \mathrm{CF}_{2} \mathrm{CF}_{2} \mathrm{O}-, \quad 3 \mathrm{~F}\right),-84.42\left(\mathrm{bs},-\mathrm{OC}\left(\mathrm{CF}_{3}\right)=\mathrm{CF}_{\mathbf{a}} \mathrm{F}_{\mathrm{b}}, 1 \mathrm{~F}\right),-88.40 \quad(\mathrm{~m},-$ $\left.\mathrm{OC}\left(\mathrm{CF}_{3}\right)=\mathrm{CF}_{\mathrm{a}} \underline{\mathbf{F}}_{\mathrm{b}}, 1 \mathrm{~F}\right),-130.32\left(\mathrm{~s}, \mathrm{CF}_{3} \mathrm{CF}_{2} \mathrm{CF}_{2} \mathrm{O}-, 2 \mathrm{~F}\right),-144.83\left(\mathrm{~m},-\mathrm{C} \underline{\mathbf{F}}\left(\mathrm{CF}_{3}\right) \mathrm{CF}_{2} \mathrm{O}-, \mathrm{n}=8.59 \mathrm{~F}\right) ; \delta{ }^{13} \mathrm{C}$ NMR $\left(100 \mathrm{MHz}, \mathrm{C}_{6} \mathrm{D}_{6}, \mathrm{C}_{6} \mathrm{~F}_{6}, 25{ }^{\circ} \mathrm{C}\right.$, see Figure S2): $102.52\left(\right.$ dsext, ${ }^{1} \mathrm{~J}_{\mathrm{CF}}=265.8 \mathrm{~Hz},{ }^{2} \mathrm{~J}_{\mathrm{CF}}=35.6 \mathrm{~Hz},-$ $\left.\mathrm{O} \underline{\mathbf{C F}}\left(\mathrm{CF}_{3}\right) \mathrm{CF}_{2^{-}}\right), 106.34\left(\right.$ tsext, $\left.{ }^{1} \mathrm{~J}_{\mathrm{CF}}=265.37 \mathrm{~Hz},{ }^{2} \mathrm{~J}_{\mathrm{CF}}=38.81 \mathrm{~Hz}, \mathrm{CF}_{3} \underline{\mathbf{C F}}_{2} \mathrm{CF}_{2} \mathrm{O}-\right), 115.87\left(\mathrm{td},{ }^{1} \mathrm{~J}_{\mathrm{CF}}=287.86\right.$ $\left.\mathrm{Hz},{ }^{2} \mathrm{~J}_{\mathrm{CF}}=30.75 \mathrm{~Hz},-\mathrm{CF}\left(\mathrm{CF}_{3}\right) \underline{\mathbf{C}} F_{2} \mathrm{O}-\right), 117.73\left(\mathrm{qd},{ }^{1} \mathrm{~J}_{\mathrm{CF}}=286.13 \mathrm{~Hz},{ }^{2} \mathrm{~J}_{\mathrm{CF}}=32.90 \mathrm{~Hz},-\mathrm{CF}\left(\mathbf{C F}_{3}\right) \mathrm{CF}_{2} \mathrm{O}-\right)$, $157.57\left(\mathrm{t},{ }^{1} \mathrm{~J}_{\mathrm{CF}}=301.45 \mathrm{~Hz},-\mathrm{OC}\left(\mathrm{CF}_{3}\right)=\underline{\mathbf{C F}}_{2} ;\right.$ MALDI-TOF $($ see Figure S3) $(\mathrm{Li}+)=1485.390(\mathrm{n}=7)$, $1651.248(\mathrm{n}=8), 1817.471(\mathrm{n}=9), 1983.517(\mathrm{n}=10), 2149.560(\mathrm{n}=11), 2315.606(\mathrm{n}=12), 2481.648(\mathrm{n}=13)$, 2647.687(n=14), 2813.722( $\mathrm{n}=15), 2979.756(\mathrm{n}=16), 3145.777(\mathrm{n}=17), 3311.800(\mathrm{n}=18) ; \quad I R: v_{\max } / \mathrm{cm}^{-1}$ $1765\left(\mathrm{C}=\mathrm{CF}_{2}\right.$ str.), 1377 ( $\mathrm{C}=\mathrm{CF}_{2}$ asym str.), 1306, 1233s (C-F str), 1178b (C-F asym str.), 1126 (C-O stretch), 1026 (=CF 2 sym str.), 981 (C-O scissoring), 807 (- $\mathrm{CF}_{3}$ str), 746, 651.

\subsubsection{Radical Copolymerization of oligo(HFPO)-PIPE with VDF}

General Procedure: The radical polymerizations of VDF and the PIPE macromonomer were performed in thick borosilicate glass Carius tubes (normal tube dimensions $=1.9 \mathrm{~cm}$ diameter $\mathrm{x} 13 \mathrm{~cm}$ length $\mathrm{x} 2 \mathrm{~mm}$ thickness; small tube dimensions $=1.9 \mathrm{~cm}$ diameter $\times 6 \mathrm{~cm}$ length $\times 2 \mathrm{~mm}$ thickness) flame sealed and rounded on one end and end-to-end joined to a smaller $8 \mathrm{~mm}$ diameter x $9.5 \mathrm{~cm}$ length $\mathrm{x} 2 \mathrm{~mm}$ thickness tube for vacuum line connection. In a typical copolymerization, a pre-determined amount of the macromonomer, radical initiator, and an appropriate volume of Freon® 113 was added into the Carius tube. The Carius tube was then placed on a special metal vacuum-line manifold containing an intermediate cylinder from which the drop of pressure was beforehand calibrated with the amount (in grams) of VDF. The contents of the tube were degassed by a minimum of three cycles of freeze-thaw for the removal of oxygen. Finally, the required VDF amount was vacuum transferred into the Carius tube frozen in liquid 
nitrogen. The $8 \mathrm{~mm}$ diameter portion of the tube was subsequently flame-sealed under dynamic vacuum while the bottom of the tube was still located in liquid nitrogen. The tube was placed in a capped, zinc plated steel pipe to warm to room temperature (padded with cotton), and this pipe was subsequently place in water bath, shaken and heated to $90{ }^{\circ} \mathrm{C}$ for $14-24$ hours. The initial clear, colorless solution became white and powdery $(96.5 \% \mathrm{VDF})$ or tan and waxy $(80-90 \% \mathrm{VDF})$. After the reaction was complete, the tube was frozen in liquid nitrogen, opened, warmed to room temperature, and the product transferred into a flask for isolation under vacuum at $50{ }^{\circ} \mathrm{C}(9 \mathrm{mmHg})$. The isolated copolymers were then weighed to assess yield. Solubility testing yielded good solubility in acetone, moderate solubility in DMF and THF, and poor solubility in trifluorotoluene. NMR analysis was performed in acetone with capillary inserts filled with $\mathrm{C}_{6} \mathrm{D}_{6}$.

Reaction \#1 [3.5 mol\%PIPE/96.5 mol\%VDF, see Figure S4]: In a Carius tube, $1.0039 \mathrm{~g}(0.6792 \mathrm{mmol})$ oligo(HFPO)-PIPE, $9.01 \mathrm{~g}$ of 1,1,2-trichloro-1,2,2-trifluoroethane, $0.75 \mathrm{~g}$ (11.7 mmol) VDF, $0.2366 \mathrm{~g}$ (0.5045 mmol) PPFR were added. After the reaction and drying, $1.7152 \mathrm{~g}$ of white powdered polymer was obtained in $97.8 \%$ yield.

Reaction \#2 [10 mol\%PIPE/90 mol\%VDF, see Figure S5]: In a small Carius tube, $1.2154 \mathrm{~g}(0.579 \mathrm{mmol})$ oligo(HFPO)-PIPE, 4 mL g of Freon®113, 0.30 g (4.6 mmol) VDF, 0.0957 g (0.2041 mmol) PPFR were added. After the reaction and drying, $1.1818 \mathrm{~g}$ pale tan waxy polymer was obtained in $78.0 \%$ yield.

Reaction \#3 [15 mol\%PIPE/85 mol\%VDF, see Figure S6]: In a small Carius tube, $0.965 \mathrm{~g}(0.6529 \mathrm{mmol})$ oligo(HFPO)-PIPE, $4 \mathrm{~g}$ of Freon® 113, $0.15 \mathrm{~g}$ (2.343 mmol) VDF, $0.013 \mathrm{~g}$ (0.02772 mmol) PPFR were added. After the reaction and drying, $1.000 \mathrm{~g}$ pale tan waxy polymer was formed in $89.7 \%$ yield.

Reaction \#4 [20 mol\%PIPE/80 mol\%VDF, see Figure S7]: In a small Carius tube, $1.3626 \mathrm{~g}(0.9219 \mathrm{mmol})$ oligo(HFPO)-PIPE, $4 \mathrm{~g}$ of Freon®113, 0.15g (2.34 mmol) VDF, $0.014 \mathrm{~g}$ (0.028 mmol) PPFR were added. After the reaction and drying, $1.3720 \mathrm{~g}$ opaque white tacky but waxy polymer was formed in $90.7 \%$ yield. Characterization: ${ }^{19} \mathrm{~F}\left(376 \mathrm{MHz}, \mathrm{C}_{6} \mathrm{D}_{6}\right.$ capillary/Acetone, $\left.25{ }^{\circ} \mathrm{C}, \delta\right)$ : -61.3 $\left(\mathrm{C}_{3} \mathrm{CH}_{2}\right.$ - chain end), -70.2 ($\left.\mathrm{CF}_{2} \mathrm{C}\left(\mathrm{CF}_{3}\right)(\mathrm{ORf}) \mathrm{CH}_{2^{-}}, 3 \mathrm{~F}\right)-81.6$ (bs, $\left.\mathrm{CF}_{3} \mathrm{CF}_{2} \mathrm{CF}_{2} \mathrm{O}-, 2 \mathrm{~F}\right),-82.5$ (bs, $\left.\mathrm{CF}_{3} \mathrm{CF}_{2} \mathrm{CF}_{2} \mathrm{O}-, 3 \mathrm{~F}\right),-79$ to -84 ($\left.\left[\mathrm{CF}\left(\mathrm{CF}_{3}\right) \mathrm{C} \underline{\mathbf{F}}_{2} \mathrm{O}\right]-\right), \quad-90.3$ to $-95.8 \quad\left(-\underline{\mathrm{CF}}_{2^{-}} \quad\right.$ of $\mathrm{VDF}$, normal head-to-tail addition); $-109.4 \quad(-$ 
$\left.\mathrm{CH}_{2} \mathrm{C}_{2} \mathrm{CF}_{2} \mathrm{C}\left(\mathrm{CF}_{3}\right) \mathrm{CH}_{2^{-}}, 2 \mathrm{~F}\right),-112.3\left(-\mathrm{CH}_{2} \mathrm{CF}_{2} \mathrm{CF}_{2} \mathrm{C}\left(\mathrm{CF}_{3}\right) \mathrm{CH}_{2^{-}}\right),-113.8$ and $-116.0\left(\mathrm{CH}_{2}-\mathrm{C}_{2}-\mathrm{C}_{2}-\mathrm{CH}_{2}\right.$

reverse VDF head to head addition), -130.7 (bs, $\left.\mathrm{CF}_{3} \mathrm{C}_{2} \mathrm{CF}_{2^{-}}, 2 \mathrm{~F}\right),-145.8$ (bm, $\left.-\left[\mathrm{C} \underline{\mathbf{F}}\left(\mathrm{CF}_{3}\right) \mathrm{CF}_{2} \mathrm{O}\right]-, 7 \mathrm{x} 1 \mathrm{~F}\right)$.

\subsection{Preparation of poly[VDF-g-oligo(HFPO)-PIPE] graft copolymers thin films}

Thin solid coating were prepared by casting using acetone as the solvent. Films with a thickness of ca. 10 $\mu \mathrm{m}$ were obtained. The fluorinated films were characterized after complete solvent evaporation: $150{ }^{\circ} \mathrm{C}$ for $30 \mathrm{~min}$ and then at RT for $24 \mathrm{~h}$.

\section{Results and Discussion}

\subsection{Synthesis of oligo(hexafluoropropylene oxide)-PIPE}

First, in other to maximize the yield of PIPE, the phenyl lithium concentration was determined using N-benzylbenzamide in THF when it reached its blue end-point. ${ }^{23}$ The phenyl lithium was added to the primary iodide as close to stoichiometry as possible to avoid any side products. Second, the perfluorohexane was purified with phenyl lithium to remove any trace amounts of hydrogen containing fluorohexane. If the hydrogen containing fluorohexane is not removed, the hydrogen is acidic enough to destroy the oligo(hexafluoropropylene oxide) perfluorocarbanion formed in the non-polar hexane/perfluorohexane solvent system. Third, the oligo(HFPO) primary iodide was lowered in temperature to $-78{ }^{\circ} \mathrm{C}$ in hexane/perfluorohexane and left at this temperature for a miniumum of 45 minutes prior to the phenyl lithium addition. The temperature is important to stabilize the lithium perfluorocarbanion. If there is any excess of phenyl lithium added, it will form a cascade of side products as reported in a former work. ${ }^{18}$ Finally, the lithium perfluorocarbanion was slowly warmed from $-78{ }^{\circ} \mathrm{C}$ to room temperature over an average of $3.5 \mathrm{~h}$ to generate the desired product (see Figures S1-S3). Phenyl adducts, which are impurities in the PIPE, can reach as high at $28 \%$ if the conditions are not achieved carefully. The ${ }^{19}$ F-NMR one (Figure S1) exhibits two distinct peaks centered at -84.4 and $-88.4 \mathrm{ppm}$ for fluorines of $=\mathrm{CF}_{2}$. The multiplet at -66.5 ppm corresponds to the multiplet for $-\mathrm{OCF}_{3} \mathrm{C}=$. The rest of the oligomer is well labeled in the NMR spectra. The ${ }^{13} \mathrm{C}$-NMR spectrum (Figure S2) displayed the signal of the triplet assigned to the $\mathrm{CF}_{2}=$ moiety. The macromonomer oligo(HFPO)-PIPE used in this work had an average DP value of 8.6 (HFPO units ranging from 7 to 18). 


\subsection{Radical Copolymerization of oligo(hexafluoropropylene oxide)-PIPE with VDF}

PPFR, regarded as a persistent radical at room temperature, was used to initiate the radical copolymerization of oligo(hexafluoropropylene oxide)-PIPE macromonomer with VDF by generating a ${ }^{\circ} \mathrm{CF}_{3}$ radical from $80{ }^{\circ} \mathrm{C}$. Scherer et $a l .{ }^{21}$ and Ono et al. ${ }^{24}$ reported the synthesis and the thermal degradation of PPFR. The degradation occurred via a $\beta$-scission to yield a trifluoromethyl radical and perfluoro-4-methyl-3ethyl-2-pentene (E/Z forms in $8 / 3$ ratio; Scheme 2). It efficiently initiated the homopolymerizations of $\mathrm{VDF}^{25}$ or trifluoroethylene, ${ }^{26}$ the copolymerization of VDF with other fluorinated comonomers ${ }^{27,28,29}$, and the copolymerization of CTFE with isobutyl vinyl ether. ${ }^{30}$

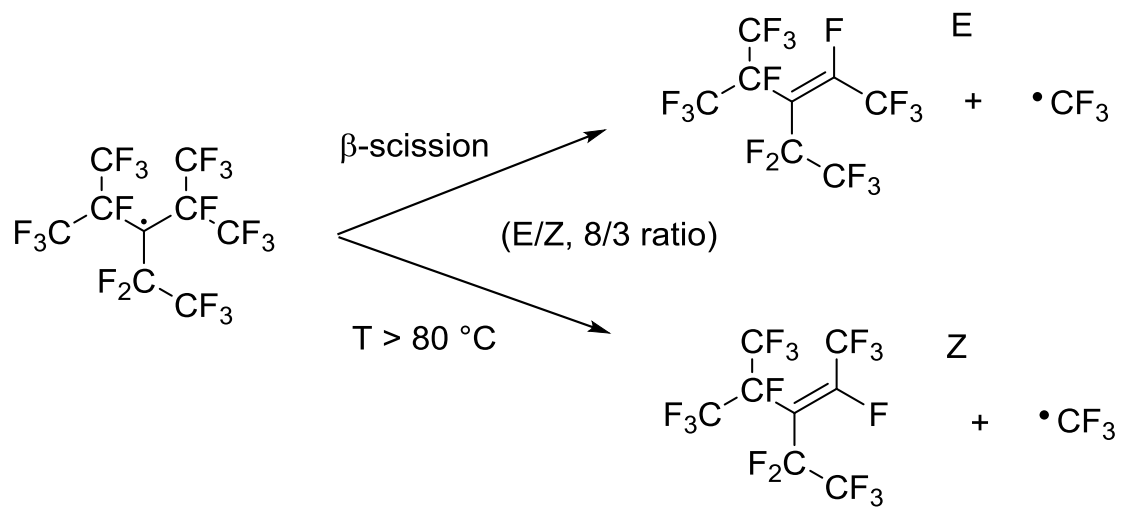

Scheme 2: perfluoro-3-ethyl-2,4-dimethyl-3-pentyl persistent radical (PPFR) initiator able to generate a trifluoromethyl radical .

Various initial $[\mathrm{PPFR}]_{\mathrm{o}} /\left([\mathrm{VDF}]_{\mathrm{o}}+[\text { oligo(HFPO)-PIPE }]_{\mathrm{o}}\right)$ molar ratios were used to carry out the radical copolymerizations in Freon $® 113$ at $90{ }^{\circ} \mathrm{C}$, the half-lives of PPFR being approximately $1 \mathrm{~h}$ at this temperature (Scheme 2).

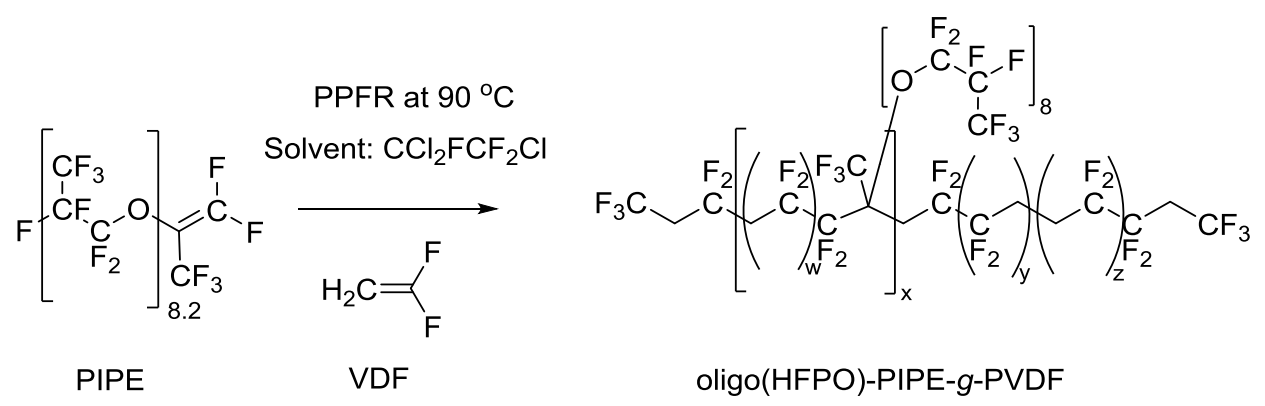


Scheme 3: Radical copolymerizations of oligo(HFPO)-PIPE macromonomer with VDF initiated by ${ }^{\circ} \mathrm{CF}_{3}$ radical generated by $\mathrm{PPFR}$ at $90{ }^{\circ} \mathrm{C}$.

Previously, the copolymerization of VDF with the perfluorovinylether, oligo(HFPO)-PVE was disclosed. ${ }^{29}$ However, no study has been reported on the unprecedented radical (co)polymerization of oligo(HFPO)-PIPE macromonomer with VDF (Scheme 3). As explained below, and summarized in Table 1, four different reaction conditions were used. 1,1,2-Trichloro-1,2,2-trifluoroethane (Freon® 113) was the reaction solvent due its ability to dissolve the starting fluorinated monomers and initiator and its inability to induce any chain transfer reactions.

\subsection{Characterization of the Microstructure of poly[VDF-g-oligo(HFPO)-PIPE] graft Copolymers by ${ }^{19} \mathrm{~F}$ - NMR Spectroscopy}

To purify the resulting poly[VDF-g-oligo(HFPO)] copolymers, the polymer was first dissolved in acetone and then dried in vacuum oven for 5 to 6 hours at $60{ }^{\circ} \mathrm{C}$ under reduced pressure. Once purified, the copolymers were characterized by ${ }^{19}$ F-NMR spectroscopy (Figures 1 and S4-S7 in the Supporting Information). The ${ }^{19}$ F-NMR spectra display the presence of: i) the characteristic signals assigned to VDF in normal head to tail addition VDF-VDF dyads and reversed head to head dyads at -91 to -96 and -114 to -116 ppm, respectively, ${ }^{25,28,31,32,33,34,35}$ ii) the expected signals assigned for the oligo(HFPO) chain are centered approximately at $-80,-131$ and $-144 \mathrm{ppm}$, and the signals centered at $-70,-109$, and $-112 \mathrm{ppm}$ are attributed to $-\mathrm{CF}_{3}$ of PIPE, $-\mathrm{CF}_{2}$ - of VDF and $-\mathrm{CF}_{2}-$ of PIPE in the oligo(HFPO)-PIPE-VDF dyad, respectively. ${ }^{36,37}$

In addition, the ${ }^{19} \mathrm{~F}-\mathrm{NMR}$ spectrum also displays the disappearance of the two complex signals $-84.4 \mathrm{ppm}$ and -88.4 ppm assigned for the two fluorine atoms $\left(\mathrm{F}_{\mathrm{a}}, \mathrm{F}_{\mathrm{b}}\right)$ on the terminus end of the perfluoroisopropenyl group of the macromonomer (Figure 1).

Table 1. Experimental conditions (including the monomer concentrations) and yields for the radical copolymerization of oligo(HFPO)-PIPE with VDF, initiated by PPFR. ${ }^{\alpha}$ 


\begin{tabular}{|l|c|c|c|c|}
\hline RXN & $\begin{array}{c}{[\text { PPFR }]_{\mathbf{0}}} \\
{[\mathbf{P I P E}]_{\mathbf{o}}+[\mathbf{V D F}]_{\mathbf{o}}} \\
(\mathbf{M o l e} \text { \%) }\end{array}$ & $\begin{array}{c}\text { PIPE } \\
(\mathbf{m m o l})\end{array}$ & $\begin{array}{c}\text { VDF } \\
(\mathbf{m m o l e})\end{array}$ & $\begin{array}{c}\text { Yield } \\
(\mathbf{\%})\end{array}$ \\
\hline 1 & 4.1 & 0.6792 & 11.7 & 97 \\
\hline $2 *$ & 3.9 & 0.5790 & 4.6 & 76 \\
\hline 3 & 0.9 & 0.6529 & 2.3 & 90 \\
\hline 4 & 0.9 & 0.9219 & 2.3 & 91 \\
\hline
\end{tabular}

RXN : Run eXpirement Number

${ }^{\alpha}$ Reaction Conditions: RXN) 1-4 using Freon ${ }^{\circledR} 113$ as solvent and 52\% purity PPFR as initiator; reaction temperature: $90{ }^{\circ} \mathrm{C}$; reaction time: 14-24 hours. *initially reaction did not work due to a defect in Carius tube and/or lack of VDF pressure, the same material was re-run.

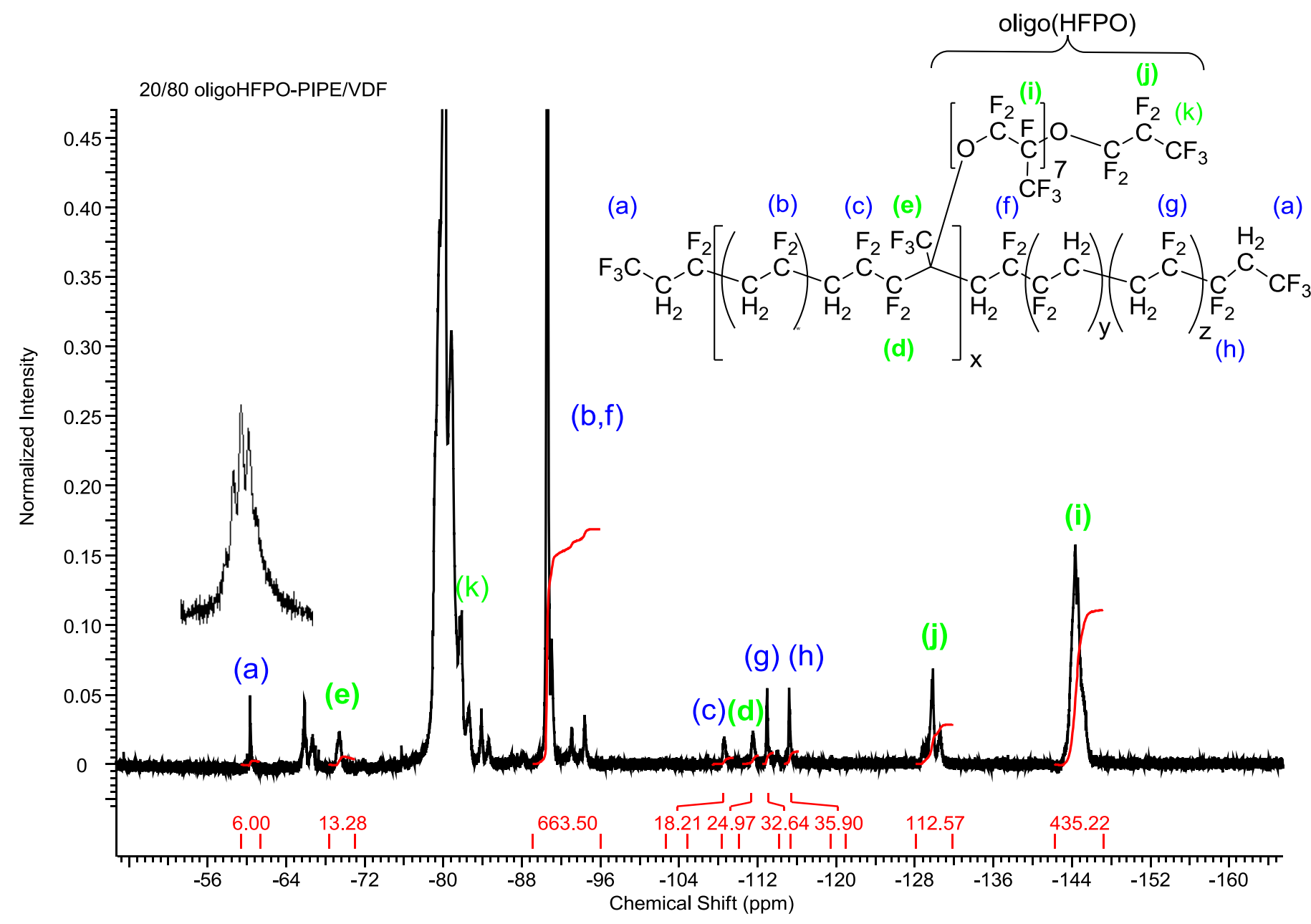

Figure 1. ${ }^{19}$ F-NMR spectrum of Poly[VDF-g-oligo(HFPO)] graft copolymer (RXN \#4, Table 1) using acetone as the solvent and $\mathrm{C}_{6} \mathrm{D}_{6}$ capillary.

To elaborate further, the central position of $-\mathrm{CH}_{2} \mathrm{CF}_{2}-\mathrm{CF}_{2} \mathrm{C}\left(\mathrm{CF}_{3}\right) \mathrm{O}$ [oligo(HFPO)]- led to a complex signal centred at approximately $-122 \mathrm{ppm}$. Other characteristic signals for oligo(HFPO) are assigned to - 
$\mathrm{CF}_{2} \mathrm{O}$ and $-\mathrm{CF}_{3}$ and are located between $-78 \mathrm{ppm}$ and $-86 \mathrm{ppm}$; whereas the peaks centered at -82.5 and $130.7 \mathrm{ppm}$ are assigned to the trifluoromethyl $\left(\mathrm{CF}_{3} \mathrm{CF}_{2} \mathrm{CF}_{2} \mathrm{O}-\right)$ and the difluoromethylene $\left(\mathrm{CF}_{3} \mathrm{CF}_{2} \mathrm{CF}_{2} \mathrm{O}-\right)$ at the beginning of the oligo(HFPO) chain, respectively. The signal at $-145.8 \mathrm{ppm}$ is assigned to the tertiary fluorine in the $-\left[\mathrm{C} \underline{\mathbf{F}}\left(\mathrm{CF}_{3}\right) \mathrm{CF}_{2} \mathrm{O}\right]-$ group of the repeat unit within PIPE macromonomer. ${ }^{38,39,40}$ The signal centered at approximately $-70.2 \mathrm{ppm}$ represents the pendant $\mathrm{CF}_{3^{-}}$group from the original PIPE moiety, but now part of the polymeric backbone $\left[-\mathrm{CF}_{2} \mathrm{C}\left(\mathrm{CF}_{3}\right)(\mathrm{O}\right.$-oligo(HFPO)-]. We believe several of the other peaks ranging from -66 to $-68 \mathrm{ppm}$ are also part of the same $\mathrm{CF}_{3}$ - from PIPE, but are due to reverse addition to the VDF monomer.

An additional feature present in the ${ }^{19} \mathrm{~F}-\mathrm{NMR}$ spectrum is the characteristic quintet $\left({ }^{3} \mathrm{~J}_{\mathrm{FH}}={ }^{4} \mathrm{~J}_{\mathrm{FF}}=10\right.$ $\mathrm{Hz}$ ) assigned to the trifluoromethyl end-group in $\mathrm{CF}_{3}-\mathrm{CH}_{2} \mathrm{CF}_{2}$ - centered at $-61 \mathrm{ppm}$. This evidences that the $\cdot \mathrm{CF}_{3}$ radical reacts selectively to the $=\mathrm{CH}_{2}$ side of VDFand confirmed previous studies from Tedder and Walton's and Améduri's teams. ${ }^{41,42,43}$ This work also confirms that PPFR initiator successfully initiated the radical copolymerizations to form moderately thermostable poly[VDF- $g$-oligo(HFPO)-PIPE] graft copolymers. The radical copolymerization initiated by ${ }^{\circ} \mathrm{CF}_{3}$ generated from the PPFR led to a 76 to $97 \%$ range for the isolated yield of the copolymer while the molecular weights ranged between 7,500 and 43,000 g.mol ${ }^{-1}$.

Although it cannot be determined by ${ }^{19} \mathrm{~F}-\mathrm{NMR}$ spectra (ca. $-83 \mathrm{ppm}$ ), there should be no reason to

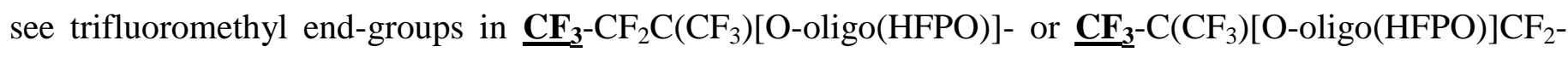
groups since highly electrophilic $\cdot \mathrm{CF}_{3}$ radical cannot react with electrophilic $\mathrm{CF}_{2}=$ and hindered $=\mathrm{C}\left(\mathrm{CF}_{3}\right) \mathrm{O}$ sites of the macromonomer. Since macroradicals terminated by $\operatorname{VDF}^{44}$ recombine exclusively, it can be anticipated that the resulting copolymers contain $\mathrm{CF}_{3^{-}}$group at both extremities, i.e. $\mathrm{CF}_{3}$-poly[VDF-goligo(HFPO)-PIPE]-CF .

The reversed amount of VDF-VDF dyad (or defect of chaining) was in a range of 4.2 and $5.3 \%$ that fits with commercially available PVDF.

3.4 Polymerization conditions that affect comonomer incorporation, yields, and molecular weights of poly[VDF-g-oligo(HFPO)-PIPE] graft copolymers 
Table 1 summarizes the conditions of radical copolymerization of VDF with the oligo(HFPO)$\mathrm{OC}\left(\mathrm{CF}_{3}\right)=\mathrm{CF}_{2}$ macromonomer, while Table 2 provides the yields and the molar masses. The general trends observed were as expected. The molar mass of the copolymer increased with an increased amount of oligo(HFPO)-PIPE (11,300 to 42,600 g. $\left.\mathrm{mol}^{-1}\right)$. Also, as the VDF mol\% feed decreased from $97 \%$ to $80 \%$, the mole\% VDF in the copolymer also decreased from $99.5 \%$ to $96.8 \%$, respectively.

\subsection{Thermal properties of poly[VDF-g-oligo(HFPO)-PIPE] graft copolymers}

Thermal properties of the graft copolymers were evaluated by TGA and DSC analyses to determine the melting point $\left(\mathrm{T}_{\mathrm{m}}\right)$, glass transition temperature $\left(\mathrm{T}_{\mathrm{g}}\right)$, and decomposition temperature at 5 wt $\%$ loss $\left(\mathrm{T}_{\mathrm{d}}^{5 \%}\right)$, reported in Table 2. In comparison to PVDF or the poly[VDF-co-perfluoromethylvinylether(PMVE)] elastomer, a significant improvement in $\mathrm{T}_{\mathrm{g}}$ and $\mathrm{T}_{\mathrm{d}}$ values was observed for poly[VDF- $g$ oligo(HFPO)-PIPE] graft copolymers. PVDF has a typical glass transition around $-40{ }^{\circ} \mathrm{C},{ }^{1,45}$ a melting temperature of $170{ }^{\circ} \mathrm{C}$, and a decomposition temperature of ca. $450{ }^{\circ} \mathrm{C}$ if $\mathrm{M}_{\mathrm{n}}>400,000 \mathrm{~g} \cdot \mathrm{mol}^{-1}$. ${ }^{1}$ Poly(VDFco-PMVE) copolymers $\left(\mathrm{M}_{\mathrm{n}}=1,250\right.$ to $\left.24,000 \mathrm{~g} / \mathrm{mol}\right)$ have $\mathrm{T}_{\mathrm{g}}$ values ranging between -66 and $-40{ }^{\circ} \mathrm{C}{ }^{46,47}$ and $\mathrm{T}_{\mathrm{d}}{ }^{10 \%}$ varying from 205 to $305^{\circ} \mathrm{C}$ but the amount of PMVE copolymerized with VDF was a much higher percentage $(8-46 \%)$ than those of the copolymers presented in this present study. Comparing directly with the thermal properties of elastomers made from VDF and the polymerizable oligo(HFPO)-PVE, PPFR initiated poly[VDF-g-oligo(HFPO)-PVE] graft copolymer of 45,000 g.mol ${ }^{-1}$ containing $98 \mathrm{~mol} \%$ VDF, displays $\mathrm{T}_{\mathrm{m}}$ of $157^{\circ} \mathrm{C}, \mathrm{T}_{\mathrm{g}}$ of $-79^{\circ} \mathrm{C}$ and thermal decomposition temperature at $50 \%$ in air $\left(\mathrm{T}_{\mathrm{d}}{ }^{50 \%}\right)$ of 475 ${ }^{\circ} \mathrm{C} .{ }^{29}$ Whereas poly(VDF-g-oligo(HFPO)-PIPE) graft copolymer of 42,600 g. $\mathrm{mol}^{-1}$ containing $97 \mathrm{~mol} \%$ VDF displays $\mathrm{T}_{\mathrm{m}}$ of $141{ }^{\circ} \mathrm{C}, \mathrm{T}_{\mathrm{g}}$ of $-81{ }^{\circ} \mathrm{C}$ and thermal decomposition temperature in nitrogen $\left(\mathrm{T}_{\mathrm{d}}{ }^{50 \%}\right)$ of $290{ }^{\circ} \mathrm{C}$.

Table 2, the $\mathrm{T}_{\mathrm{gS}}$ of all four graft copolymers were ca. $-82{ }^{\circ} \mathrm{C}$ and seemed quasiindependent from their molar masses ranging from 7,500 to $42,600 \mathrm{~g} \cdot \mathrm{mol}^{-1}$. The $\mathrm{T}_{\mathrm{g}}$ values of these copolymers were only slightly lower compared to those of the copolymers of VDF with oligo(HFPO)PVE, poly[VDF- $g$-oligo(HFPOPVE)] graft copolymer, which ranged from -79 to $-54{ }^{\circ} \mathrm{C}$ versus their molecular weights ranging from 
25,000 to 77,000 g.mol ${ }^{-1}{ }^{29}$ The slight lowering in glass transitions temperature with oligo(HFPO)$\mathrm{C}\left(\mathrm{CF}_{3}\right)=\mathrm{CF}_{2}$ compared to oligo $(\mathrm{HFPO})-\mathrm{OCF}=\mathrm{CF}_{2}$ could be due to the additional pendent $-\mathrm{CF}_{3}$ groups in the copolymer. However, the melting points were shown to be comparable to copolymers of poly[VDF- $g$ oligo(HFPO)-PVE)] achieved from PPFR. The $\mathrm{T}_{\mathrm{m}}$ values (Table 2) ranged from 141 to $163{ }^{\circ} \mathrm{C}$ due to the percentage of VDF within the polymer (96.8 to $99.5 \%$ ). Interestingly, not only $\mathrm{T}_{\mathrm{m}}$ decreases going from the product obtained by reaction \#1 to the one achieved from reaction \#4, but the crystalline part of the copolymer is also significantly reduced, being the latter copolymer almost completely amorphous ${ }^{48}$ (Figures S8-S11 in the Supporting Information). Also, poly[VDF-g-oligo(HFPO)-PIPE] graft copolymers demonstrate less crystalline behavior as those of poly(VDF-co-HFP) and poly(VDF-co-PMVE) copolymers due to the introduction of oligo(HFPO)-PIPE within PVDF. ${ }^{49}$

Figure 2 exhibits the TGA thermograms and their first derivative for the four copolymers, under nitrogen. The poly[VDF-g-oligo(HFPO)-PIPE] graft copolymers display two main degradation stages centered at around $280{ }^{\circ} \mathrm{C}$ and $470{ }^{\circ} \mathrm{C}$. By decreasing the VDF percentage in the copolymers (i.e., going from reaction \#1 to reaction \#4), the weight loss at lower temperature becomes more significant, thus reducing the thermal stability of the copolymer. However, all the copolymers have a moderate thermal resistance (in Table 2 the $\mathrm{T}_{\mathrm{d}}^{5 \%}$ values are reported), comparable to poly[VDF- $g$-oligo(HFPO)-PVE] ${ }^{7}$ but higher than poly(VDF-co-PMVE) copolymers.

The thermal stability of the copolymer is an interesting feature to consider due to the microstructure of the oligo(HFPO)-PIPE versus the oligo(HFPO)-PVE-based polymers with VDF. By comparing the thermal stability of PTFE and PFA, it is known that PFA displays a lower thermal stability. ${ }^{50}$ The most likely reason for this decrease in thermal performance is due to the pendant -ORf group. The pendant group of PVE-base polymers contains $-\mathrm{CF}_{2} \mathrm{CF}\left(\mathrm{OR}_{\mathrm{f}}\right)-\mathrm{CH}_{2} \mathrm{CF}_{2}-$ microstructures whereas that of PIPE-based polymers is $-\mathrm{CF}_{2} \mathrm{C}\left(\mathrm{CF}_{3}\right)\left(\mathrm{OR}_{\mathrm{f}}\right)-\mathrm{CH}_{2} \mathrm{CF}_{2}$. If the $-\mathrm{OR}_{\mathrm{f}}$ moeity cleaves from the backbone of the polymer, PVE-based systems should form $-\mathrm{CF}_{2} \mathrm{CF}^{\circ} \mathrm{CH}_{2} \mathrm{CF}_{2}$ - radicals which with the resonance of the fluorine to the secondary radical shoud help stabilizing the system. However, PIPE-based copolymer should form tertiary $\mathrm{CF}_{2} \mathrm{C}^{\circ}\left(\mathrm{CF}_{3}\right) \mathrm{CH}_{2} \mathrm{CF}_{2}$ - radicals. With only the inductive effect, $\mathrm{CF}_{3}$ group adjacent to the radical should 
destabilize the radical and causes the degradation of the polymer to occur at lower temperature. Another reason for unsatistfactory thermal stability may arise from the nature of the TGA cruciblse (alumina) which may affect the decomposition behavior of the PFPAE side-chain as reported by Sianesi et al. and in more recent work by Howell. ${ }^{51,52}$ Obviously, more work needs to be accomplished to understand their decomposition behavior.

Although the efficiency of the persistent radical (PPFR) was already tested in previous studies, ${ }^{25,27}$ it was reported that the molar masses and thermostability of the resulting PVDF or PTrFE homopolymers ${ }^{25,26}$ or copolymers of VDF with hexafluoropropylene, trifluoroethylene, 3,3,3-trifluoropropene, 2trifluoromethacrylic acid, ${ }^{28}$ and oligo(HFPO)- $\mathrm{PVE}^{29}$ increased with a lower initiator concentration. ${ }^{27}$ However, in this study, oligo(HFPO)-PIPE reacted more completely with VDF using PPFR than oligo(HFPO)-PVE.

Table 2. Experimental Conditions and Results for the Radical Copolymerization of oligo(HFPO)PIPE with VDF. ${ }^{\beta}$

\begin{tabular}{|c|c|c|c|c|c|c|c|c|c|}
\hline \multirow[b]{2}{*}{$\mathbf{R X N}$} & \multirow[b]{2}{*}{ initiator (mole) } & \multicolumn{2}{|c|}{ VDF( mol \%) } & \multirow[b]{2}{*}{$\begin{array}{l}\text { Yield } \\
(\%)\end{array}$} & \multirow[b]{2}{*}{$\begin{array}{l}M_{n}\left(g \cdot \mathrm{mol}^{-1}\right) \\
\text { by }{ }^{19} \mathrm{~F}-\mathrm{NMR}\end{array}$} & \multirow[b]{2}{*}{$\begin{array}{l}x \\
(\%)\end{array}$} & \multirow[b]{2}{*}{$\begin{array}{l}\mathbf{T}_{\mathrm{m}} \\
\left({ }^{\circ} \mathbf{C}\right)\end{array}$} & \multirow[b]{2}{*}{$\begin{array}{l}\mathbf{T}_{\mathrm{g}} \\
\left({ }^{\circ} \mathrm{C}\right)\end{array}$} & \multirow[b]{2}{*}{$\begin{array}{l}\mathbf{T}_{\mathbf{d}}{ }^{5 \%} \\
\left({ }^{\circ} \mathbf{C}\right)\end{array}$} \\
\hline & & Feed $(\%)$ & Copolymers(\%) & & & & & & \\
\hline 1 & 0.50 & 97 & 99.5 & 97 & 11,300 & 11.9 & 163 & -81 & 271 \\
\hline $2 *$ & 0.20 & 90 & 97.9 & 76 & 7,500 & 4.9 & 155 & -82 & 227 \\
\hline 3 & 0.03 & 85 & 97.6 & 90 & 12,000 & 3.2 & 143 & -83 & 231 \\
\hline 4 & 0.03 & 80 & 96.8 & 91 & 42,600 & 2.4 & 141 & -81 & 224 \\
\hline
\end{tabular}


(a)

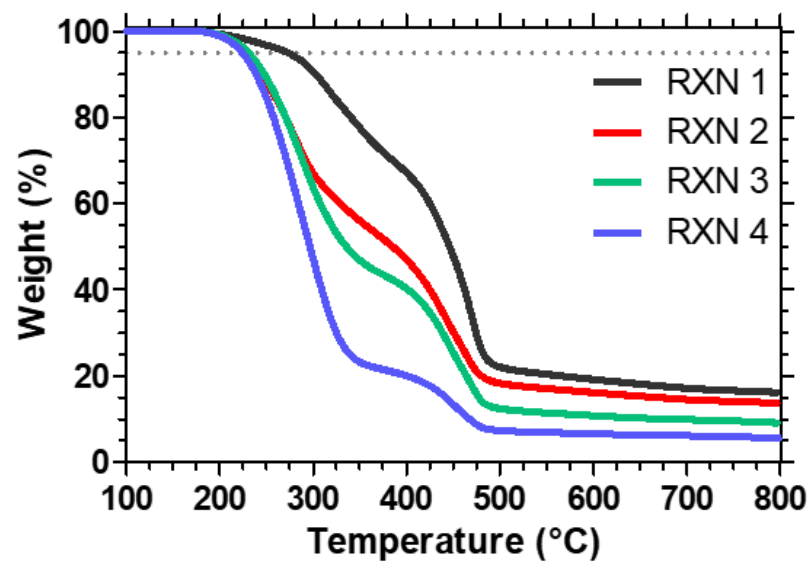

(b)

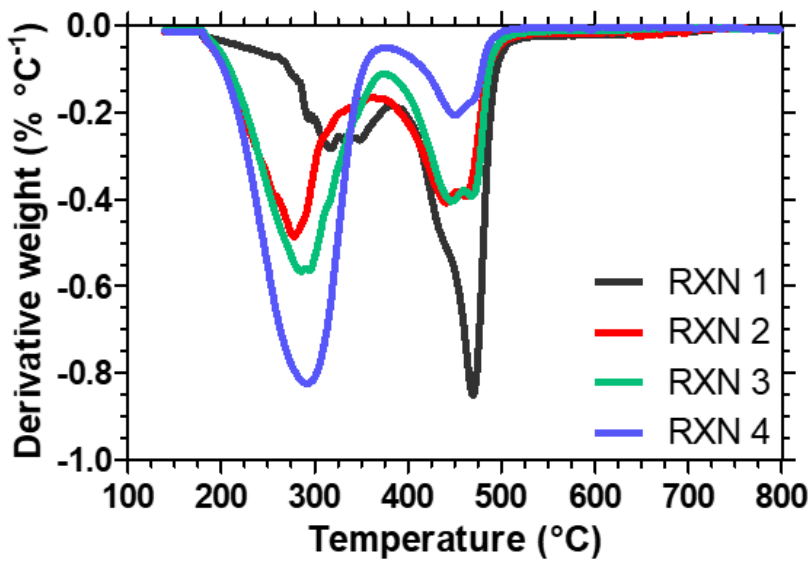

Figure 2: Thermal gravimetric analysis thermograms, under nitrogen, of poly[VDF- $g$-oligo(HFPOPIPE] graft copolymers: weight loss (a) and first derivative of the weight (b) as a function of temperature.

\subsection{Surface properties of poly[VDF-g-oligo(HFPO)-PIPE] graft copolymers films}

Thin solid films were then prepared with the four poly[VDF-g-oligo(HFPO)-PIPE] graft copolymers, and their wettability was evaluated by using water and hexadecane as test liquids. The results are reported in Table 3 and in Figure S12 in the Supporting Information. As expected, considering their large fluorine content and their structure, the graft copolymers are both hydrophobic and oleophobic, showing very high values of water contact angle $\left(\theta_{\text {water }}\right)$ and hexadecane contact angle $\left(\theta_{\text {hexadecane }}\right)$. In particular, $\theta_{\text {water }}$ is higher than $132^{\circ}$ for all studied copolymers, which is a value significantly increased compared to that of PVDF homopolymer $\left(\approx 80^{\circ} \text { to } 82^{\circ}\right)^{53,54}$ and even of PVDF copolymers with fluoroalkyl side chains (e.g., poly(VDF-co-fluoroalkyl 2- trifluoromethacrylate) were demonstrated to have $\left.\theta_{\text {water }} \approx 114^{\circ}\right) .{ }^{55}$ In another example, a network composed of PVDF and PFPAE showed a water contact angle of $\theta_{\text {water }} \approx 120^{\circ}{ }^{56}$ This reduced surface wettability is due to the higher fluorine content compared to PVDF homopolymer and 
especially to the presence of the oligo(HFPO) side chain, which is expected to enhance the hydro- and oleophobicity of the copolymers. ${ }^{2,57,58}$

In addition, the surface energy $\gamma$ of the poly[VDF-g-oligo(HFPO)-PIPE] graft copolymers is extremely low as see in Table 3, where surface energies range from 12.1 to $13.5 \mathrm{mN} \mathrm{m}^{-1}$, with a polar component $\left(\gamma^{p}\right)$ almost equal to zero. The surface energy are comparable to poly(methylpropenoxyfluoroalkylsiloxanes $\left(11.8\right.$ to $\left.16.0 \mathrm{mN} \mathrm{m}^{-1}\right)$ and approaching the performanceof poly(perfluoroalkylmethacrylate)s, which range from 6.1 to $7.8 \mathrm{mN} \mathrm{m}^{-1}{ }^{58}$ These results evidence the low wettability of the films toward both polar and apolar liquids, which is a relevant property of fluoropolymers when used for the preparation of advanced coatings.

Table 3. Contact angle with water $\left(\theta_{\text {water }}\right)$ and with hexadecane $\left(\theta_{\text {hexadecane }}\right)$, and surface energy $\gamma$ (divided in the dispersive $\gamma^{\mathrm{d}}$ and the polar $\gamma^{\mathrm{p}}$ component) of thin films of poly(VDF-g-oligo(HFPOPIPE) graft copolymers.

$\begin{array}{cccccc}\text { RXN } & \boldsymbol{\theta}_{\text {water }}\left({ }^{\circ}\right) & \boldsymbol{\theta}_{\text {hexadecane }}\left({ }^{\circ}\right) & \gamma\left(\mathbf{m N ~ m}^{-\mathbf{1}}\right) & \gamma^{d}\left(\mathbf{m N ~ m}^{-\mathbf{1}}\right) & \gamma^{p}\left(\mathbf{m N ~ m}^{-\mathbf{1}}\right) \\ 1 & 133.9 \pm 3.9 & 72.5 \pm 1.9 & 12.1 & 11.6 & 0.5 \\ 2 & 133.5 \pm 2.7 & 68.3 \pm 3.7 & 13.5 & 12.9 & 0.6 \\ 3 & 132.7 \pm 2.6 & 68.8 \pm 5.0 & 13.2 & 12.7 & 0.5 \\ 4 & 133.3 \pm 5.3 & 71.3 \pm 3.3 & 12.4 & 12.0 & 0.4\end{array}$

\section{Conclusions}

This unprecendeted study demonstates that the $\mathrm{CF}_{2}=\mathrm{C}\left(\mathrm{CF}_{3}\right) \mathrm{O}$ - moiety can be copolymerized with VDF to form $\mathrm{CF}_{3}$-poly[VDF-g-oligo(HFPO)-PIPE]- $\mathrm{CF}_{3}$ graft copolymers, which were fully characterized. The nature of the end-groups arose from PPFR that released a ${ }^{\circ} \mathrm{CF} 3$ radical able to initiate the radical copolymerization of VDF with PIPE. These poly[VDF-g-oligo(HFPO)-PIPE] graft copolymers, as potential thermoplastic elastomers, endowed with very low $\mathrm{T}_{\mathrm{g}}$ values (as low as $-83^{\circ} \mathrm{C}$ ), were prepared in fairly high yields with a complete conversion of the oligo(HFPO)-PIPE macromonomer. Varying the feed amount of the macromonomer governed the intake of the comonomers. Since the resulting graft copolymers were not soluble in common organic solvents for characterization by size exclusion chromatography (SEC) or 
viscosimetry, ${ }^{19} \mathrm{~F}-\mathrm{NMR}$ spectroscopy was the only method to determine their microstructures and molar masses (which reached up to 42,600 g.mol ${ }^{-1}$ ). From the data, various features have been highlighted: 1) ${ }^{\circ} \mathrm{CF}_{3}$ radical from PPFR reacts onto methylene site of VDF selectively; 2) as expected, VDF has higher reactivity in polymerization and to the initiator over oligo(HFPO)-PIPE; 3) the highest molar mass of the graft copolymer achieved was $42,600 \mathrm{~g}^{\mathrm{mol}}{ }^{-1}$; 4) they were driven by the mole\% of oligo(HFPO) perfluroisopropenyl ether rather than the initiator concentration; 5) the synthesized copolymers possessed interesting thermal properties, such as melting temperature ranging from 150 to $163{ }^{\circ} \mathrm{C}, \mathrm{T}_{\mathrm{g}}$ of around $-83{ }^{\circ} \mathrm{C}$ , but only had a maximum stability measured of $271{ }^{\circ} \mathrm{C}$ under nitrogen. Finally, the newly synthesized poly[VDF-g-oligo(HFPO)-PIPE] graft copolymers show excellent low wettability properties, both with polar and apolar liquids, having a surface energy as low as $12 \mathrm{mN} / \mathrm{m}$.

\section{ASSOCIATED CONTENT}

Supporting Information. ${ }^{13} \mathrm{C},{ }^{19} \mathrm{~F}-\mathrm{NMR}$, and MALDI-TOF spectra of oligo(hexafluoropropylene oxide) perfluroisopropenyl ether (PIPE) macromonomer and ${ }^{19}$ F-NMR spectra of poly[VDF- $g$-oligo(HFPO)-PIPE] graft copolymers, DSC thermograms of poly[VDF- $g$-oligo(HFPO)-PIPE] graft copolymers are provided.

\section{AUTHOR INFORMATION}

\section{Corresponding Authors}

*Prof. C. M. Friesen: Tel: +01-604-513-2121 (3220); E-Mail: chad.friesen@twu.ca

*Dr. B. Améduri: Tel: +33-467-144-368; E-Mail: bruno.ameduri@enscm.fr

\section{ACKNOWLEDGMENTS}

The authors thank the European Union's Horizon 2020 research and innovation program under grant agreement No. 690917-PhotoFluo, Natural Sciences and Engineering Research Council of Canada (NSERC), Discovery Grants Program RGPIN-2015-05513for, and the French Fluorine Network (Gis Fluor). Dr. Jon Howell from E. I. DuPont for their gift of hexafluoropropylene oxide, Krytox ${ }^{\circledR}$ primary iodide, and 1,1,2-trichloro-1,2,2-trifluoroethane (Freon® 113). 
${ }^{1}$ A. L.Moore, Fluoroelastomers Handbook: The Definitive User's Guide and Databook; Taylor \& Francis, William Andrew Publishing: Norwich, NY, 2006, 241-278.

${ }^{2}$ C.M. Friesen,; B. Améduri, Prog. Polym. Sci., 2018, 81, 238-280.

${ }^{3}$ H.Allcock, in B. Améduri,; H. Sawada, (eds) Fluorinated Polymers: From Fundamental to Practical Synthesis and Applications; Royal Society of Chemistry: Oxford, 2017; Vol. 2,; Chapter 3, 54-79

${ }^{4}$ B.Améduri, Encyclop. Polym. Sci. Tech., John Wiley \& Sons, Inc. 2012.

${ }^{5}$ A.T. Worm, World Patent 2000/012574, 2000 (assigned to Dyneon LLC).

${ }^{6}$ J.Wu, B. R. Lund, B. Batchelor, D. K. Dei, S. M. Liff, D. W. Jr. Smith, J.Fluor.Chem., 2015, 180, $227-$ 233.

${ }^{7}$ C. M. Friesen, B. Améduri, Macromolecules, 2015, 48 (19), 7060-7070.

${ }^{8}$ G.Lopez, B. Améduri, J.P. Habas, Eur. Polym. J., 2017, 95, 207-2015.

${ }^{9}$ K. Yoon, S. Woo, K. Song, S. Choi, US Patent 20030228537 A1, 2003 (assigned to Samsung Electronics Co).

${ }^{10}$ T. Narita, T. Hagiwara, H. Hamana, K. Enomoto, Y.Yoshida,Y. Inagaki, Macromol.Rapid Comm., 1998, 19(9), 485-491.

${ }^{11}$ T. Narita, H. Hamana, M. Takeshita, H. Fujiwara, J.Fluor. Chem., 2003, 124 (2), 197-201.

12 T. Okumura, S. Nishimura, M. Akatsuka, European Patent 1,263,076 A2, 2002 (assigned to Hitachi, Ltd.).

${ }^{13}$ H. Fujiwara, T. Narita, H. Hamana, J. Fluor. Chem., 2004, 125(9), 1279-1285.

${ }^{14}$ T.Narita, H. Hamana, F. Sekiya, Y. Nojima, J.Polym. Sci.: Part A, Polym. Chem., 2007, 45(5), 908-910.

${ }^{15}$ H. Li, A. B. Jackson, N. J. Kirk, K. A. Mauritz,R. F. Storey, Macromolecules, 2011, 44, 694-702.

${ }^{16}$ C. Huang, Kudzma, L. V. World Patent 2010/123880 A1, 2010 (assigned to Baxter International Inc.)

${ }^{17}$ C. Qian, T. Nakai, Tetrahedron Lett., 1988, 29, 4119-4122.

${ }^{18}$ T. J. Burgess, A. D. G. Pasiuk, B. J. Jelier, C. M. Friesen, Chem. Comm., 2018, 54, 10439-10442.

${ }^{19}$ K. Nakagawa, Y. Ishida, Kolloid-Zeitsch. Zeitsch. Polym., 1973, 251, 103-107.

${ }^{20}$ K. Nakagawa, Y. Ishida, J. Polym. Sci.: Part B; Polym. Phys., 1973, 11, 2153-2171.

${ }^{21}$ K. V. Jr. Scherer, T. Ono, K. Yamanouchi, R. Fernandez, P. Henderson, H. Goldwhite, J. Am. Chem. Soc. 1985, 107, 718-719.

${ }^{22}$ T. Ono, K. Ohta, J. Fluorine Chem., 2014, 167, 198-202.

${ }^{23}$ A. F. Burkhart, J. M. Chong, N. Nielsen, J. Organometallic Chem., 1997, 542, 281-283.

${ }^{24}$ T. Ono, H. Fukaya, M. Nishida, N. Terasawa, T. Abe, Chem. Commun., 1996, 1579-1580.

${ }^{25}$ F. Boschet, T. Ono, B. Améduri, Macromol. Rapid Commun., 2012, 33, 302-308.

${ }^{26}$ M. Colpaert, S. Banerjee, V. Ladmiral, T. Ono, B. Améduri, Polym. Chem., 2018, 9, 894-903.

${ }^{27}$ Y. Patil, T. Ono,B. Ameduri, ACS Macro Lett. 2012, 1, 315-320.

${ }^{28}$ Y. Patil, A. Allaeddine,T. Ono, B. Ameduri, Macromolecules, 2013, 46, 3092-3106.

${ }^{29}$ C.M. Friesen, B. Améduri, Macromolecules, 2015, 48(19), 7060-7070.

${ }^{30}$ G. Puts, G. Lopez,P. Crouse, B. Améduri, RSC Adv., 2015, 5, 41544-41554.

${ }^{31}$ A. D. Asandei, O. I. Adebolu, C. P. Simpson, J. Am. Chem. Soc., 2012, 134, 6080-6083.

${ }^{32}$ P. Yogesh, T. Ono, B. Améduri, ACS Macro Lett., 2012, 1, 315-320.

${ }^{33}$ M. Pianca, F. Barchiesi, G. Esposto, S. Radice, J. Fluorine Chem. 1999, 95, 71-84.

${ }^{34}$ E. B. Twum, C. Gao, X. Li, E. F. McCord, P. A. Fox, D. F. Lyons, P. L. Rinaldi, Macromolecules, 2012, 45, 5501-5512.

${ }^{35}$ J. Guiot, B. Améduri, B. Boutevin, Macromolecules, 2002, 35,8694-8707.

${ }^{36}$ X. Li, E. F. McCord, S. Baiagern, P. Fox, J. L. Howell, S. K. Sahoo, P.L. Rinaldi, Magn. Res. Chem., 2011, 49, 413-424.

${ }^{37}$ L.I. Costa, G. Storti, M. Morbidelli, L. Ferro, O. Scialdone, G. Filardo, A. Galia, Macromolecules, 2010, 43, 9714-9723.

${ }^{38}$ J. Lapčík, O. Gimello, V. Ladmiral, C. M. Friesen, B. Améduri, Polym. Chem., 2015, 6, 79-96. 
${ }^{39}$ S. V. Kostuk, E. Ortega, F. Ganachaud, B. Boutevin, B. Améduri, Macromolecules, 2009, 42, 612-619.

${ }^{40}$ X. Li, E.F. McCord, P. A. Fox, J. Howell, P.L. Rinaldi, J. Polym. Anal. Charact., 2012, 17,161-188.

${ }^{41}$ J. N. Cape, A. C. Greig, J. M. Tedder, J. C. Walton, J. Chem. Soc., Faraday Trans., 1975, 1, 592-601.

${ }^{42}$ B. Améduri, C. Ladaviere, F. Delolme, B. Boutevin, Macromolecules, 2004, 37, 7602-7609.

${ }^{43}$ B. Ameduri, T. Billard, B. Langlois, J. Polym. Sci. Polym. Chem., 2002, 40, 4538-4549.

${ }^{44}$ R. Timmerman, W. Greyson, J. Appl. Polym. Sci., 1962, 6, 456-460.

45 J.T. Goldbach, R. Amin-Sanayei, W. He, H. Henry, W. Kosar, A. Lefebvre, G. O'Brien, D. Vaessen, K. Wood S. Zerafati, in B. Améduri, H. Sawada, (eds) Fluorinated Polymers: From Fundamental to Practical Synthesis and Applications; Royal Society of Chemistry: Oxford, 2017, Vol. 2, Chapter 6, pp127-157.

${ }^{46}$ B. Otazaghine, L. Sauguet, M. Boucher, B. Ameduri, Eur.Polym. J. 2005, 41, 1747-1756.

${ }^{47}$ C. Boyer, B. Ameduri, M.H. Hung, Macromolecules, 2010, 43, 3652-3663.

${ }^{48}$ Y. Okamoto, F. Mikeš, K. Koike, and Y. Koike, in Handbook of Fluoropolymer Science and Technology (eds D. W. Smith, S. T. Iacono and S. S. Iyer), 2014, John Wiley \& Sons, Inc., Hoboken, NJ, USA; chapt. 16, 377-392.

${ }^{49}$ G. Moggi, P. Bonardelli, C.J. Bart, Polym. Bull. 1982, 7, 115-122.

${ }^{50}$ S. Ebnesajjad, "Fluoroplastics Metl Processible Fluoropolymers: The Definitive User's Guide and Databook." Plastics Design Library Handbook Series, Norvich, NY, 2003, Vol. 2, 408.

${ }^{51}$ D. Sianesi, V. Zamboni, R. Fontanelli, M. Binaghi, Wear, 1971, 18, 85-100.

52 J.L. Howell, C. M. Friesen, A. B. Shtarov, J. S. Thrasher, A. Waterfeld, E. W. Pérez, J. F. Sullivan, J. Synth. Lub., 2007, 24(4), 227-234.

${ }^{53}$ A. Kaynak, T. Mehmood, X.J. Dai, K. Magniez, A. Kouzani, Materials, 2013, 6(8), 3482-3493.

${ }_{54}^{54}$ E. N. Dalal, Langmuir, 1987, 3 (6), 1009-1015.

${ }^{55}$ M. N. Wadekar, Y. R. Patil, B. Améduri, Macromolecules, 2014, 47, 13-25.

${ }^{56}$ G. Lopez, M. Guerre, B. Améduri, J.P. Habas, V. Ladmiral, Polym. Chem., 2017, 8, 3045-3049.

57 A. Vitale, R. Bongiovanni, B. Améduri, Chem. Rev., 2015, 115 (16), 8835-8866.

${ }^{58}$ E. Barbu, R.A. Pullin, P. Graham, P. Eaton, R.J. Even, J.D. Smart, T.G. Nevell, J. Tsibouklis, Polymer, 2002, 43, 1727-1734. 
